\title{
Consejo de Ancianos: historia oculta detrás de una tradición en la Mosquitia
}

Jorge Matamoros B.

"Algo anda mal"l

El presente trabajo es un intento por brindar una lectura de los eventos independentistas protagonizados por los consejos de ancianos de las comunidades miskitas de la Costa Caribe nicaragüense. Tomando en cuenta este objetivo, el texto es producto de una reflexión cuyos insumos proceden de la observación directa de los hechos y del auxilio de la opinión calificada de periodistas locales, miembros de otras disciplinas profesionales y comunitarios participantes en los eventos. El texto se estructura en tres secciones. La primera es una valoración de los acontecimientos en la región. En la segunda se subraya someramente la importancia simbólico-cultural de los ancianos en la idiosincrasia comunitaria. La tercera y última sección intenta presentar el concepto de Nación Comunitaria de la Mosquitia y las demandas básicas de los ancianos.

\section{VALORACION DE LOS ACONTECIMIENTOS}

Con el concepto de "Nación Comunitaria de la Mosquitia," el movimiento de los Consejos de Ancianos de las comunidades miskitas de la Costa Caribe nicaragüense dio a conocer ante la comunidad local y nacional lo que fue denominado como la "Declaración de Independencia de la Mosquitia." La declaración incluía una serie de medidas ante el gobierno de Nicaragua: facultad de los ancianos para negociar la explotación petrolera, en la plataforma marina del Caribe, y los otros recursos naturales; obligación del Estado nicaragüense de pagar la deuda histórica en concepto de resarcimiento de los daños humanos y ecológicos-ambientales por años de explotación mineral y forestal en la región; retención de los ingresos fiscales en la región; plazo de seis meses (19 de octubre) para el traspaso formal del gobierno regional a los ancianos, con previa auditoria internacional del actual periodo de administración regional, entre otras medidas.

En un acto político singular, el evento fue efectuado en la ciudad de Bilwi, sede del gobierno de la Región Autónoma del Atlántico Norte (RAAN), el día 19 de abril del presente año, ante una nutrida asamblea comunitaria. La asamblea contó en su momento con una concurrencia masiva de comunitarios pocas veces vista en la historia local de movilizaciones políticas. Los comunitarios procedían de los barrios de Bilwi, comunidades aledañas a ésta y prácticamente de todas las zonas miskitas de la región.
Entre los atractivos notorios de la asamblea se observaba el uso magnífico de simbologías comunitarias y analogías bíblicas de procesos de liberación aplicadas en las luchas locales. Este tipo de técnicas, según se podía observar en las actitudes colectivas, constituían recursos especiales en la construcción y el fortalecimiento de la identidad comunitaria y estimulaba el potencial subversivo de la identidad étnica.

El acto complementario del evento fue la elección e instalación del Wihta Tara (Guía Máximo) y su gabinete de doce miembros. En un sufragio con voto directo y público, el reverendo Héctor Williams, pastor de la Iglesia Evangélica Asamblea Cristiana, fue escogido como el primer Wihta Tara de los Consejos de Ancianos. Las dos figuras (Wihta Tara y gabinete) no forman parte de las estructuras tradicionales de los Consejos de Ancianos. No obstante, la idea fue altamente valorada por los comunitarios en la estrategia de fortalecer la imagen y el rol de los ancianos como institución social en la tradición comunitaria ante los retos de los problemas comunitarios contemporáneos.

Este evento fue seguido más recientemente por los acontecimientos del 19 de octubre. En esta ocasión, el acto de los comunitarios expresó acciones de manifestaciones y protestas contra el Gobierno Regional y el Gobierno Central. El objetivo de la manifestación era tomar las instalaciones del complejo de la Casa de Gobierno de la

\footnotetext{
1 La expresión designa el título de publicación de los resultados de un estudio llevado a cabo por la Universidad de las Regiones Autónomas de la Costa Caribe Nicaragüense (URACCAN) sobre ataques de histeria colectiva que sufría la población en las comunidades de Río Coco en diciembre, 2003.
} 
RAAN, para ajustar las medidas de la declaratoria de la independencia.

Enfrentándose a un numeroso grupo de antimotines de la policía enviados desde Managua y a grupos sandinistas de choques organizados supuestamente por la Secretaria Regional del FSLN y Stedman Fagoth (primera figura de la dirigencia miskita de los años 80 y actual ministro del Instituto de la Pesca), los manifestantes, bajo intensas lluvias de tormentas tropicales, desistieron. A esta decisión de los manifestantes contribuyeron, a mi juicio, dos factores. En primer lugar, la intensidad de las bombas lacrimógenas de los antimotines y la lluvia de pedradas a punta de huleras lanzadas por los atacantes sandinistas. Por otro lado, el propio convencimiento de muchos de los manifestantes de lo ilógico de la acción.

El discurso y las pretensiones de independencia son cuestionables por lo irreal. En la práctica, nadie ni la mayoría de los comunitarios ni los mismos promotores de la idea lo creen. Para estos últimos, la idea de independencia es solamente un recurso de movilización, aunque moralmente pareciera una trágica manipulación política. No obstante, independientemente de la falsedad y la incoherencia de los discursos de independencia, el movimiento de los ancianos goza de respaldo popular activo y potencial. En consecuencia, tiene legitimidad. Esto es lo sustantivo para comprender y prestar atención a estos hechos, cuya responsabilidad recae en el Gobierno Regional y el Gobierno Central.

Hay consenso amplio en la sociedad, que las causas que impulsan a los comunitarios hacia este tipo de movilizaciones radican en la inconformidad y demandas locales derivadas de la atrofia del proyecto de autonomía por la conducción arbitraria del mismo. La autonomía es, tras casi veinte años de vigencia, simplemente un proyecto de confiscación de los derechos y bienes comunitarios a beneficio de grupos de cúpulas políticas locales que se atribuyen el rol de intermediación comunitaria ante

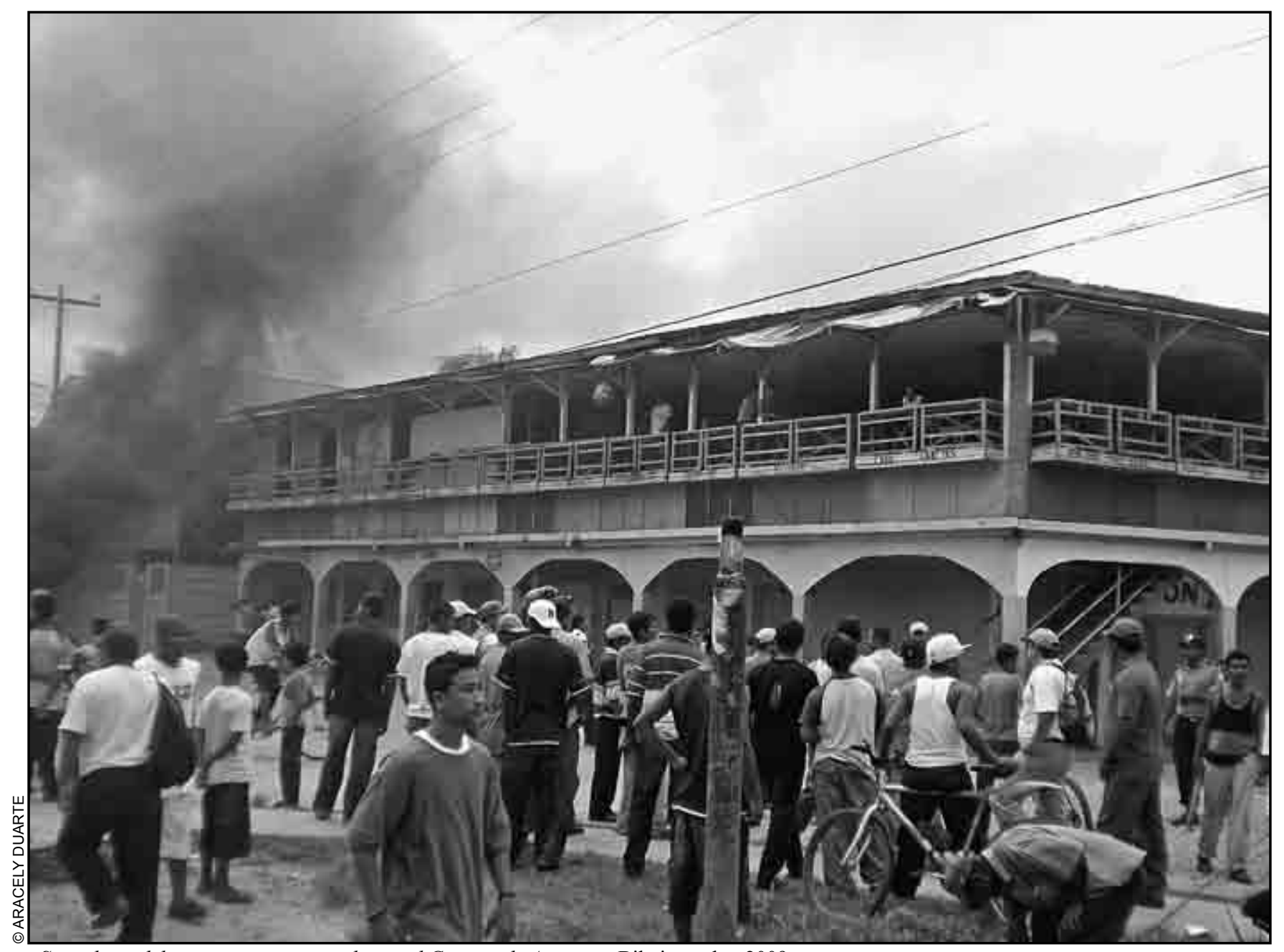

Seguidores del movimiento promovido por el Consejo de Ancianos. Bilwi, octubre 2009. 
el Gobierno Central. La idea de una autonomía plena parece más bien pertenecer al mundo de las utopías. De seguir la misma tendencia, en breve estará la región ante una situación de calamidad económica, social, política y ecológico-ambiental.

Entre los dos actos promovidos por los ancianos, el de mayor resonancia fue el de la reciente manifestación del 19 de octubre, por los matices de violencia que exhibieron. A la luz de dichos acontecimientos, a manera de lecciones aprendidas, a continuación un intento por puntualizar algunas observaciones:

\section{Actores y contradicciones}

En el protagonismo de los acontecimientos regionales figuran claramente tres actores, siendo ellos: la población pasiva, la mayoría, con potencial de identificación hacia cualquiera de los grupos protagonistas; la población activa, organizada mayoritariamente al lado del movimiento de los ancianos y, en alguna proporción, con cualquiera de los partidos; finalmente, los grupos de cúpulas étnicas locales, vinculados a cualquiera de los partidos nacionales, con privilegios en los espacios del poder regional.

Una observación del comportamiento de los actores en los acontecimientos regionales permite identificar dos líneas de pensamiento que marcan las contradicciones y determinan la actitud de los protagonistas. Dichas líneas son, en primer lugar, el pensamiento comunitario. Esto es pensar como indígena o costeño con sentido de identidad étnicocomunitario. En segundo lugar, el pensamiento estatal. Esto es pensar en función de los intereses del Estado, obedeciendo las directrices de los partidos nacionales, cuyos propósitos son el control de los recursos naturales y el clientelismo político de la población.

En la correlación de fuerzas, la línea del pensamiento étnico-comunitario es la mayoría predominante en la población, mientras que la línea del pensamiento estatal

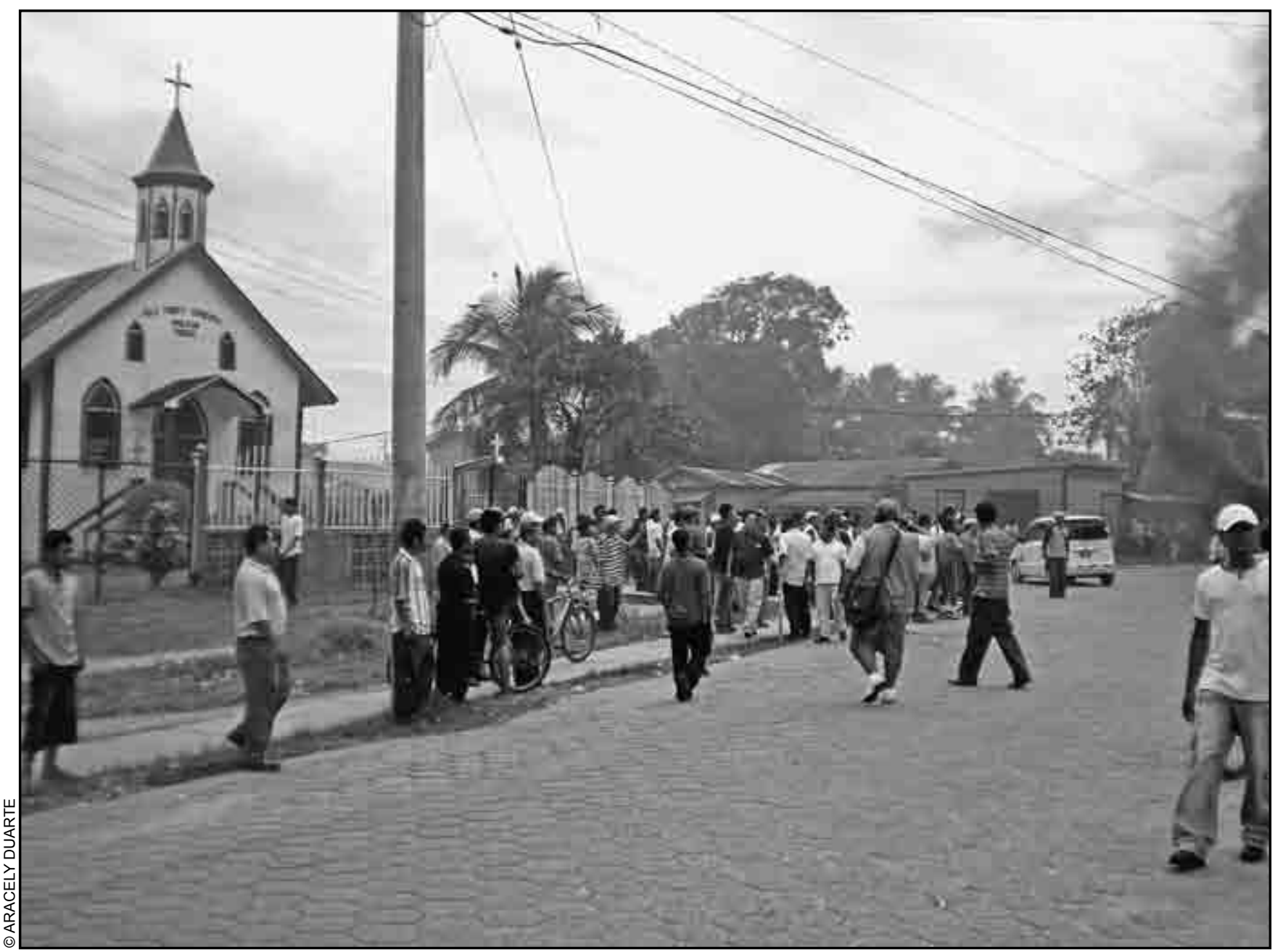

Curiosos y seguidores en las jornadas de protesta del Consejo de Ancianos. Bilwi, octubre 2009. 
es sostenida por grupos locales vinculados al poder regional y a cualquiera de los partidos. La salida del conflicto pasa por equilibrar o conciliar, estas dos líneas de pensamiento, en negociaciones sobre el concepto del proyecto autonómico (modelo económico, control de los recursos naturales, sistema institucional, agenda social, etcétera), territorialidad, espacios de poder, derecho de organización, entre otros.

\section{Participación}

En los acontecimientos del 19 de octubre, al igual que en los de abril, la participación de la población fue masiva. La masividad en las últimas movilizaciones hubiese sido mucho mayor si los obstáculos, impedimentos y controles establecidos por la Policía Nacional, así como las acciones desplegadas por los grupos políticos locales, no impidieran el acceso de la población de las periferias al centro de la ciudad de Bilwi. Más aún, según opinión de muchos observadores locales, si el discurso político de los líderes de las protestas fuera más coherente, las calles de la ciudad de Bilwi hubiesen sido, por primera vez en su historia, teatro de manifestaciones multiétnicas de grandes proporciones. Esto indica la magnitud de la inconformidad reinante en la población por la situación económica y política de la región y el potencial explosivo de la misma. Indica, en consecuencia, la legitimidad de los actos y la obligación que tiene el Estado de prestar atención con responsabilidad.

Otro factor que limitó una mayor participación fue la cuestión de las relaciones de parentesco. En este sentido es necesario reconocer que la estructura poblacional de las regiones autónomas, con mayor expresión en la RAAN, se basa en amplias relaciones de parentesco. Resulta que en el fondo de todos los conflictos hay también conflictos entre los grupos de parentesco, pues hay miembros de familias distribuidos en todos los lados del conflicto. Entonces, para preservar las relaciones familiares, muchos prefieren guardar distancia frente a los grandes conflictos entre los grupos políticos.

\section{Rol de los medios de comunicación: diferencia entre medios nacionales y locales}

Los grandes medios de comunicación social en el Pacifico del país, al servicio de los "sagrados intereses" privados de las élites económicas y de la clase política criolla, con lenguajes y epítetos característicos difundieron inmediatamente noticias y pensamientos asociando el acto de los ancianos con pretensiones de separatismo de los costeños. Como de costumbre, en claro acto de abuso y violación de la libertad de expresión, estos medios se encargaron de desvirtuar satanizando, ante la opinión pública, los verdaderos significados de los hechos en el Caribe.

Algunos que supuestamente apoyaban, lo hicieron con fines más inmorales aún, los de la manipulación. En este caso señalaban que la reacción de los ancianos era un acto en específico contra el abandono de la región por parte del actual gobierno sandinista. Este reduccionismo no cabe, pues la región es víctima de abandono histórico por el Estado nicaragüense desde sus orígenes. Entonces, la reacción de la población es una demanda global ante el Estado nicaragüense en su conjunto, sin consideraciones de límites de un tiempo específico.

En este mismo plano hay que reconocer el magnífico rol desempeñado por muchos medios locales de comunicación en Bilwi, en especial los programas televisivos de Raúl Davis, Radio Caribe, Radio VECA y Radio Amor Juvenil. Estos medios asumieron posiciones críticas, comprendieron que en el fondo de las contradicciones y el caos el problema pasaba por el enfrentamiento de un pensamiento estatal versus un pensamiento étnico-comunal en el análisis, interpretación y atención de los asuntos estratégicos regionales. Así pudieron orientar la opinión pública local en la línea de la lucha contemporánea de los caribeños por reivindicaciones históricas, construcción de la democracia y las aspiraciones del desarrollo humano con pertinencia cultural en el marco del estado de derecho dentro del Estado nicaragüense.

\section{Actitudes entre los actores y el perfil del liderazgo}

Las partes en conflicto en las manifestaciones del 19 de octubre fueron directamente entre miskitos. Unos al lado de los ancianos, guiados por el Wihta Tara, y otros desde espacios de poder en el gobierno regional y miembros de distintos partidos, más propiamente YATAMA y el FSLN.

Influenciadas por el orgullo, ambas partes se negaron a dialogar. Justificaban el no diálogo argumentando cada uno tener el liderazgo legítimo, otorgado por el voto popular. Por parte de los ancianos, el orgullo fue más allá al no explicar públicamente su agenda social, económica, política y religiosa, así como no presentar a las bases un informe y perspectiva de su gestión semestral desde el 19 de abril. Este orgullo fue un grave error técnico y político, pues, no pudieron presentar un paquete de demandas 


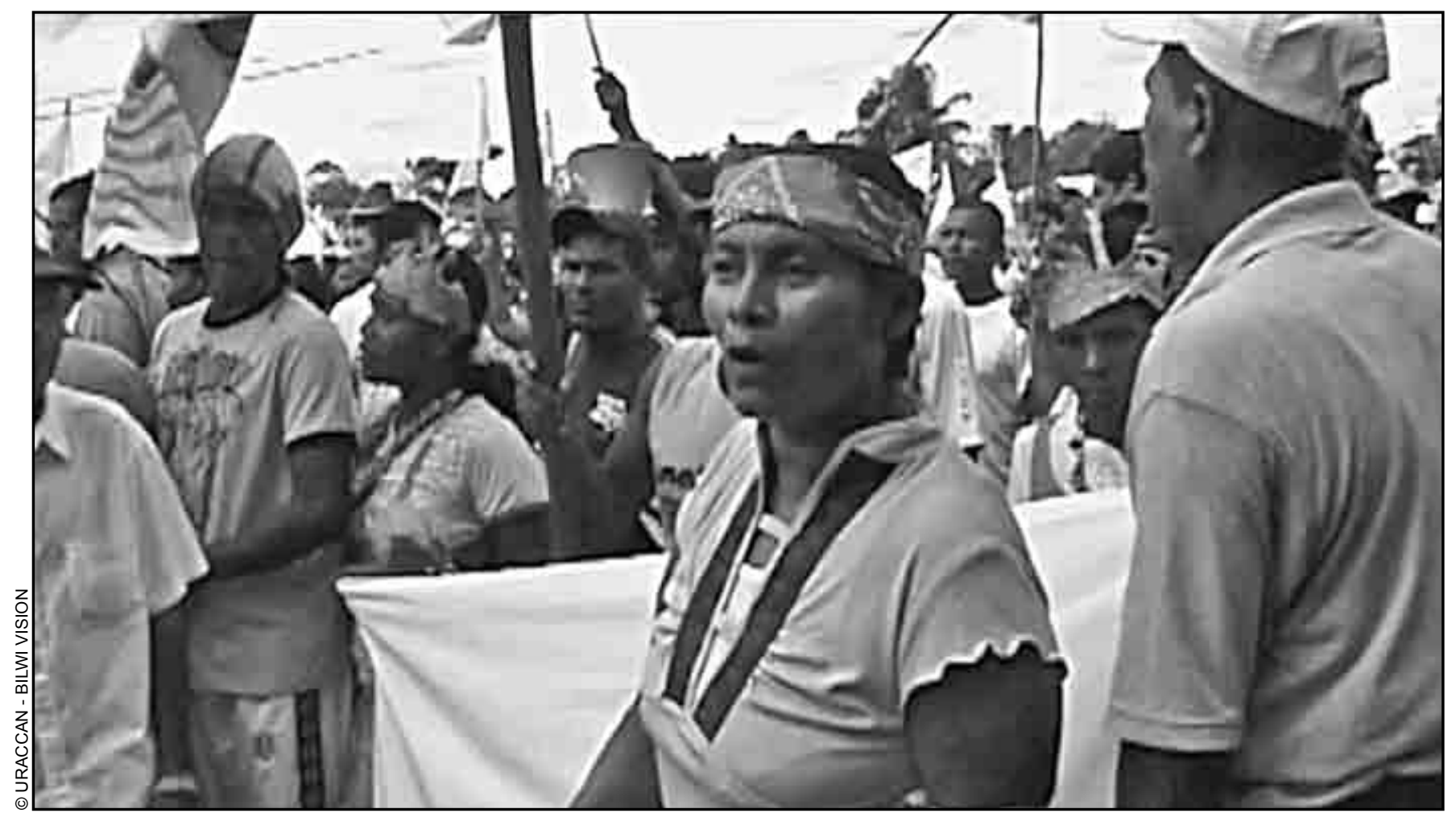

La lucha contra la corrupción y las arbitrariedades acumuladas en el proceso de autonomía es una de las banderas de este movimiento. Bilwi, octubre 2009.

regionales al gobierno central cuando los obispos aceptaron intermediar en el conflicto.

A nivel de liderazgo se estima que un $75 \%$ de la opinión popular local es favorable al movimiento de los ancianos. Pero no por la independencia, sino como reacción ante los niveles de corrupción en la administración del gobierno regional, la conducción arbitraria del proyecto autonómico y el panorama de agudización creciente de la pobreza. Se percibe también que en muchos círculos de gremios, profesionales y sectores sociales, la opinión es adversa a la idea de independencia, pero no por falta de aspiraciones sino por sentido de pragmatismo.

En el ámbito del liderazgo, otro fenómeno notorio fue el protagonismo de Fagoth y Brooklyn. En un elocuente ejemplo de metamorfosis política, producto de incongruencias de pensamientos, quizás, o tal vez por prácticas políticas no consecuentes con las causas que supuestamente defienden, o simplemente por intereses egoístas, los antaño "máximos" líderes misquitos, Stedman Fagoth y Brooklyn Rivera, en perfecta simbiosis con el pensamiento estatal, tampoco se quedaron atrás en el concierto de señalar como separatista el singular evento de sus ancianos, sin considerar que ellos mismos en su momento se valieron intensamente de la figura y la causa con que los ancianos promueven el surgimiento de sus respectivos liderazgos. Este mismo discurso fue utilizado por MISURASATA, organización étnico-miskita predecesora de YATAMA, así como el sostenimiento de los discursos de justificación cultural del alzamiento militar indígena de los años 80 contra la Revolución Popular Sandinista.

Pese a la metamorfosis de los señores del liderazgo, y a la furia de la clase política nacional, el movimiento de los ancianos simboliza la expresión y voz más auténtica de críticas y denuncias ante la danza de corrupciones y arbitrariedades acumuladas en el proceso autonómico tras casi veinte años de vigencia y los riesgos de calamidad en la situación regional. 


\section{Fortalecimiento del espíritu comunitario: gracias al "heroísmo" de los sandinistas}

Desde la perspectiva de los comunitarios, pese al infructuoso intento de tomar la Casa de Gobierno, uno de los efectos más notables de la jornada del 19 de octubre en Bilwi fue el fortalecimiento del espíritu comunitario ante la violencia institucional. Esto fue mejor pavimentado gracias a las acciones de los atacantes sandinistas. Un numeroso grupo de choque fue organizado, armado y puesto en acción, según fuentes de los ancianos, por la dirigencia local del FSLN. Los miembros de ese grupo, armados con garrotes y huleras recibían con lluvias de piedras el paso de los manifestantes por el parque local y otros puntos de la ciudad. Esta acción revivió memorias latentes de enfrentamientos de los comunitarios con el FSLN en la guerra de los ochenta. Lejos de provocar temores, las pedradas de los atacantes sandinistas estimularon el sentimiento antisandinista y forjaron el sentido de la identidad comunitaria.

\section{VALOR SIMBOLICO-CULTURAL DE LOS ANCIANOS EN LA IDIOSINCRACIA COMUNITARIA}

Entre los pueblos indígenas de la Costa Caribe nicaragüense (miskitos, mayangnas, ramas), la presencia y voz de los ancianos en los asuntos comunales tiene en el imaginario social un valor humano especial por el atributo de símbolo moral que les conceden los comunitarios a los ancianos. Este atributo proporciona mérito de institución social a los ancianos en función de reproducción de valores en el seno familiar; transmisión de historias orales de generación a generación en la comunidad y depositarios de la custodia de intereses del patrimonio comunal. En las últimas décadas, el aporte de los ancianos es creciente en la lucha por las reivindicaciones comunitarias. Es incuestionable así su contribución en la construcción de la ruta de asociatividad y capital social. Por esta tradición, los ancianos representan el núcleo simbólico y ético en la ruta de construcción de la asociatividad étnica entre los pueblos miskitos, mayangnas y ramas.

Las redes de asociatividad de los distintos pueblos indígenas, afro caribeños y comunidades étnicas, según valoración de estudios recientes del PNUD, aunque guardan importantes diferencias entre sí, sin embargo, de manera general están directamente relacionadas y consensuadas con respecto a la supervivencia económica, social y cultural de dichos pueblos, vinculadas estrechamente a la identidad étnica y a la búsqueda de organización propia para enfrentar problemas y garantizar sus derechos ante la falta de confianza y credibilidad en las instituciones del Estado y en las autoridades autonómicas regionales (PNUD, 2005: 116).

En el caso de los miskitos, el valor de los ancianos está reflejado continuamente en la historia de las movilizaciones étnicas de las últimas décadas: desde el inicio del activismo manifiesto de las comunidades miskitas ante el Estado nicaragüense en los años 60, pasando por las movilizaciones de ALPROMISU en la década de los 70 y las de MISURASATA en el período revolucionario, sin olvidar su papel en las vicisitudes de la larga experiencia de refugio en Honduras durante los años 80. En todos esos acontecimientos o momentos, las figuras protagónicas de liderazgos emergentes se valieron siempre de las iniciativas, simbologías y causas promovidas por los ancianos.

Por este expediente de los ancianos es justo reconocer que detrás de la tradición de transmisores de la historia oral y valores hacia las generaciones, la presencia de los ancianos está activa en la historia de lucha por demandas de reivindicaciones históricas ante el Estado. Historia injustamente ignorada. Uno de los errores del liderazgo de YATAMA ha sido precisamente ignorar, tras valerse muy bien de ellos, la importancia de la figura y el liderazgo especial de los ancianos en la idiosincrasia comunal. Esto explica en parte el deterioro creciente de dicha organización y su liderazgo en la actualidad.

Valiéndose de sus recursos simbólicos, los ancianos parecen actualmente estar apuntando hacia el umbral de otra opción organizativa, planteando un concepto más comunitario de autonomía: Nación Comunitaria de la Mosquitia. Esta opción sería la respuesta al síndrome de atrofia del proyecto autonómico actual. La nueva opción organizativa se fundamenta en el principio de comunitarismo, distante de todo partidarismo. El activismo de los ancianos está más fuerte en las comunidades miskitas. Se sigue potencialmente de mayangnas y ramas.

Conociendo de cerca la mística de los ancianos, ésta merece una sección especial. Pero por limitaciones del presente texto, me limito ligeramente a un sólo aspecto. Me refiero a los valores éticos de los ancianos ante la miseria de la práctica política en nuestro medio. En una comparación de relación de valores y anti valores resulta evidente la ausencia de valores humanos en los discursos y las acciones de la clase política nacional. Esto se reproduce en los grupos políticos regionales y se profundiza en circunstancias de conflictos. En contraste, los ancianos practican diariamente 
los círculos de reflexiones cuyos contenidos son, entre otros: información regional, nacional e internacional; funcionamiento de las instituciones regionales; historia de la Mosquitia; reflexión bíblica y fortalecimiento del movimiento.

Nutridos de fe en su causa, con sus bases sociales analizan, argumentan e interpretan la historia de la Mosquitia, con auxilio de analogías bíblicas de amor, paz, nación, justicia, liderazgo, valor, constancia, voluntad, unidad, territorio, opresión y liberación. Estos valores quedan simbolizados en la bandera blanca de la paz con que los ancianos acostumbran desarrollar sus eventos.

Prácticamente, los ancianos constituyen un círculo con un enfoque especial de teología. Encuentran en la Biblia la fuente de la santa subversión. O sea, la posibilidad de transformar las estructuras establecidas para procesos de emancipación. Frente a los anti valores que caracteriza el protagonismo de la clase política local y nacional, los ancianos parecen ser portadores o expresión de valores morales y sociales que la sociedad espera de la práctica política.

Aunque con infinidad de obstáculos en la ruta, pero con confianza en el capital acumulado, el soporte teológico y su fuente de inspiración en la Biblia, sienten tener cohesión para la sobre vivencia del movimiento ante cualquier adversidad. Creen con seguridad que en la ruta de liberación el Mar Rojo se abre frente al pueblo en sus orillas, teniendo a sus espaldas la espada del faraón.

Entre las características del movimiento se destaca la preocupación de los ancianos por tomar distancia de los discursos etnocentristas; el afán de construcción de consensos culturales; y el uso intenso de elementos simbólicos rescatados de la historia local, las memorias colectivas, las tradiciones comunales y las analogías bíblicas. El uso de los recursos simbólicos imprime una fuerza especial para lograr las movilizaciones, pues, las comunidades sienten encontrar en ellos satisfacción con el sentido de construcción y reconstrucción de la identidad étnica.

\section{NACION COMUTARIA DE LA MOSQUITIA Y LA DEMANDA DE LOS ANCIANOS}

El proyecto autonómico está reducido a espacios de partidos. Ante esta crisis existen actualmente, en el universo del pensamiento político regional, varios enfoques de autonomía sostenidos por diferentes actores, siendo el concepto de la Nación Comunitaria de la Mosquitia, defendido por los ancianos, uno de ellos. La Nación

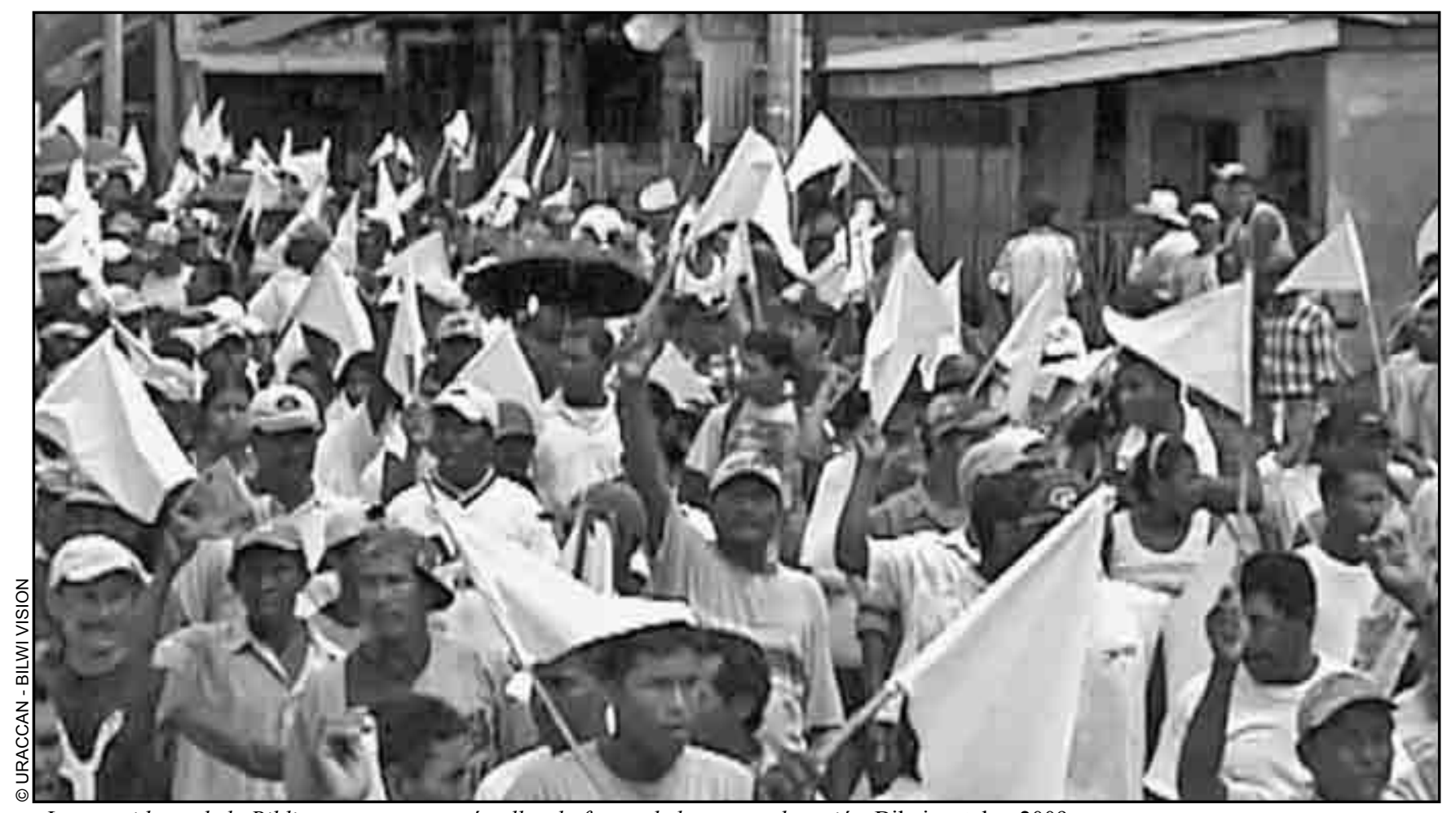

Los seguidores de la Biblia encuentran, según ellos, la fuente de la santa subversión. Bilwi, octubre 2009. 
Comunitaria de la Mosquitia, lejos de la independencia, en el sentido de soberanía que atente contra la unidad territorial nicaragüense, o acto específico contra el gobierno actual, representa un proyecto alternativo ante la percepción de fracaso del proyecto autonómico de las regiones de la Costa Caribe. Las demandas principales de los ancianos se relacionan con la organización comunitaria y la territorialidad, para poner en práctica un proyecto autonómico. A este fin aspira crear antes una instancia de inter locución comunitaria, distante y libre de influencias partidarias que garantice una representación orgánica de los pueblos indígenas y comunidades étnicas.

Para los ancianos, el concepto de nación comunitaria representa un proyecto que implica un espacio geográfico, un concepto jurídico, un valor cultural, un proyecto político-económico y una perspectiva teológica. Es decir, un proyecto de cinco componentes referido a las comunidades miskitas, sumu-mayangnas, creoles, garífunas, ramas y mestizas de la Costa Caribe. El objetivo primordial es lograr el desarrollo humano y contribuir al fortalecimiento de la democracia cultural, política y económica de la nacionalidad nicaragüense, en el sentido bien reconocido en los estudios del PNUD:

El propósito es valorar el inestimable aporte que el régimen de autonomía hace al presente y futuro de la sociedad nicaragüense al posibilitar relaciones positivas, constructivas y beneficiosas entre los pueblos y comunidades del Caribe con el Estado y la sociedad nicaragüense en su conjunto. (PNUD, 2005: 39).

Aportes al presente y futuro, internos y externos; objetivos hacia los cuales el proyecto autonómico actual no está respondiendo tras casi dos décadas de vigencia.

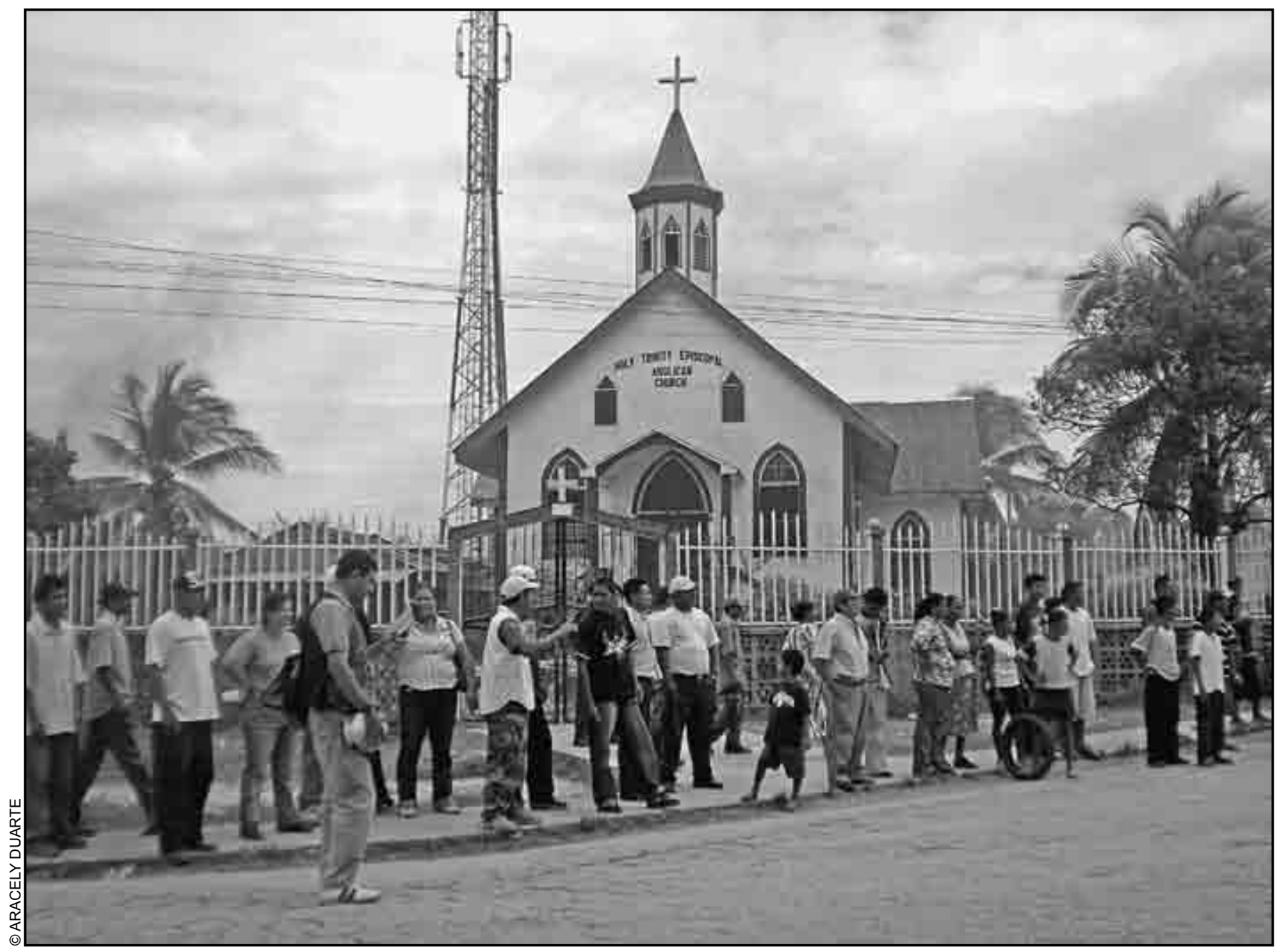

Las contradicciones internas del Consejo de Ancianos amenazan el cumplimiento de sus objetivos. Bilwi, octubre 2009. 
A continuación se presenta el concepto de nación comunitaria en grafica, preliminar:

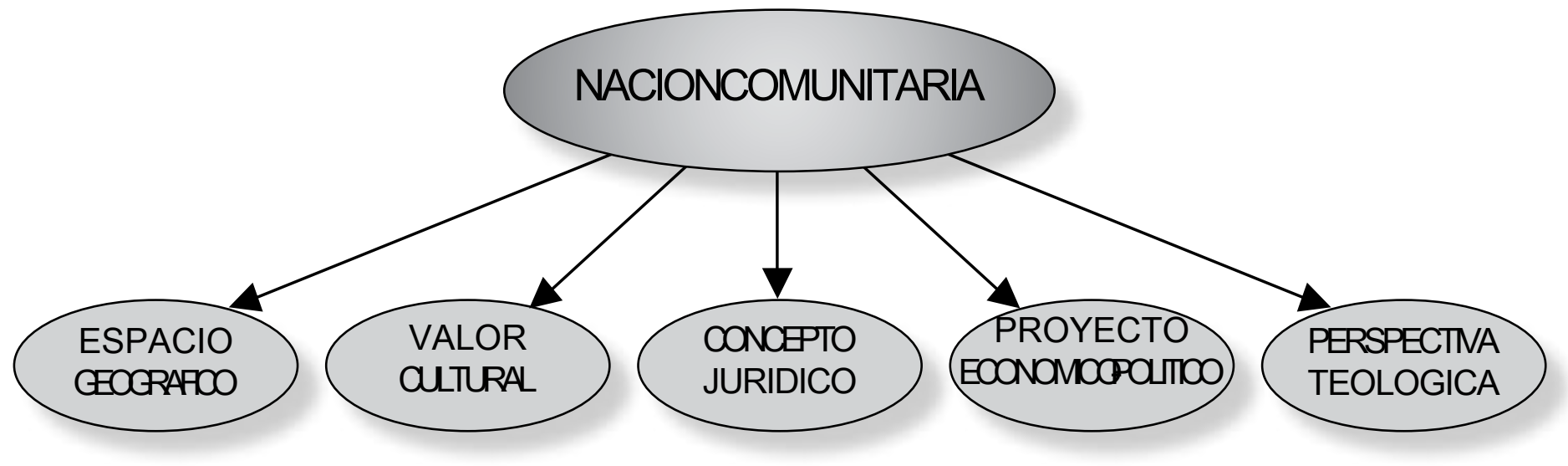

De los cinco componentes, el espacio geográfico y el valor cultural constituyen componentes centrales del proyecto de la nación comunitaria. El espacio geográfico se refiere al territorio de la Mosquitia. En esta línea de interés, el proceso de demarcación es tema de vital importancia para los ancianos. Están señalando preocupaciones con el actual proceso de demarcación, temen que al final del proceso no se logre satisfacer las expectativas de las demandas históricas de las comunidades.

Para los ancianos, el objetivo de la demarcación es resolver la contradicción, entre la Costa Caribe y el Estado nicaragüense, sobre dos conceptos de tierras construidos por el Estado en el proceso de apropiación de las tierras de la antigua Mosquitia a finales del Siglo XVIII. Dichos conceptos son "las tierras nacionales" y "las tierras comunales", conceptos con los cuales el Estado nicaragüense subclasificó y subdividió el territorio de la Mosquitia en Departamento de Zelaya y Reserva Mosquita, tras la anexión del territorio de la Mosquitia a la soberanía nicaragüense en 1894. Entonces, la demarcación implica para los ancianos recuperar espacios dentro de las llamadas tierras nacionales, trascendiendo el reducido perímetro de las tierras comunales que actualmente ocupan las comunidades.

En la línea de esta contradicción, la modalidad de demarcación constituye un elemento clave para las demandas de reivindicaciones de los pueblos y comunidades de la Costa Caribe a los derechos históricos a la tierra. En la modalidad de demarcación se define si se trata de demarcación total o parcial respecto a las tierras nacionales.

El actual proceso de demarcación se lleva a cabo reconociendo dos modalidades de demarcación: tierras comunales y bloques comunales. La modalidad de tierras comunales hace referencia a la demarcación específica de una comunidad como localidad. Por su parte, la modalidad de bloques comunales reconoce el territorio de un conjunto de comunidades que, en función de sus relaciones locales y características similares, demandan títulos colectivos de sus tierras. En cualquier caso, la modalidad de demarcación tiene que ver con si se resuelve la contradicción entre tierras nacionales y tierras comunales; a demás, cómo la demarcación se articula y satisface los criterios de territorialidad para el ejercicio de los derechos autonómicos en contexto multicultural.

\section{Mapa de demarcación}

En este sentido, los ancianos plantean la demarcación basada en la modalidad de Yapti Tasba o Madre Tierra. Se refiere esto a dos categorías y dos etapas de demarcación. En una primera etapa demarcar la llamada tierra nacional dentro de la antigua Mosquitia (Yapti Tasba), lo que fue el Departamento de Zelaya, o parte al menos. Luego, en el marco de Yapti Tasba, demarcar seis territorios étnicos correspondientes a las seis comunidades culturales: miskitos, mayangnas, creoles, ramas, garífunas y mestizos. Según los ancianos, esta modalidad ha sido la demanda histórica y constituye el elemento central para cimentar el proyecto autonómico y la construcción de relaciones inter étnicas desde la perspectiva y simbología comunitaria. Se teme que la modalidad actual de demarcación por bloques comunales no logre satisfacer estas expectativas.

En el componente de espacio cultural ocupa lugar predominante el derecho organizativo. Se refiere a la necesidad de crear una instancia de participación e interlocución comunitaria en oposición a la intermediación 


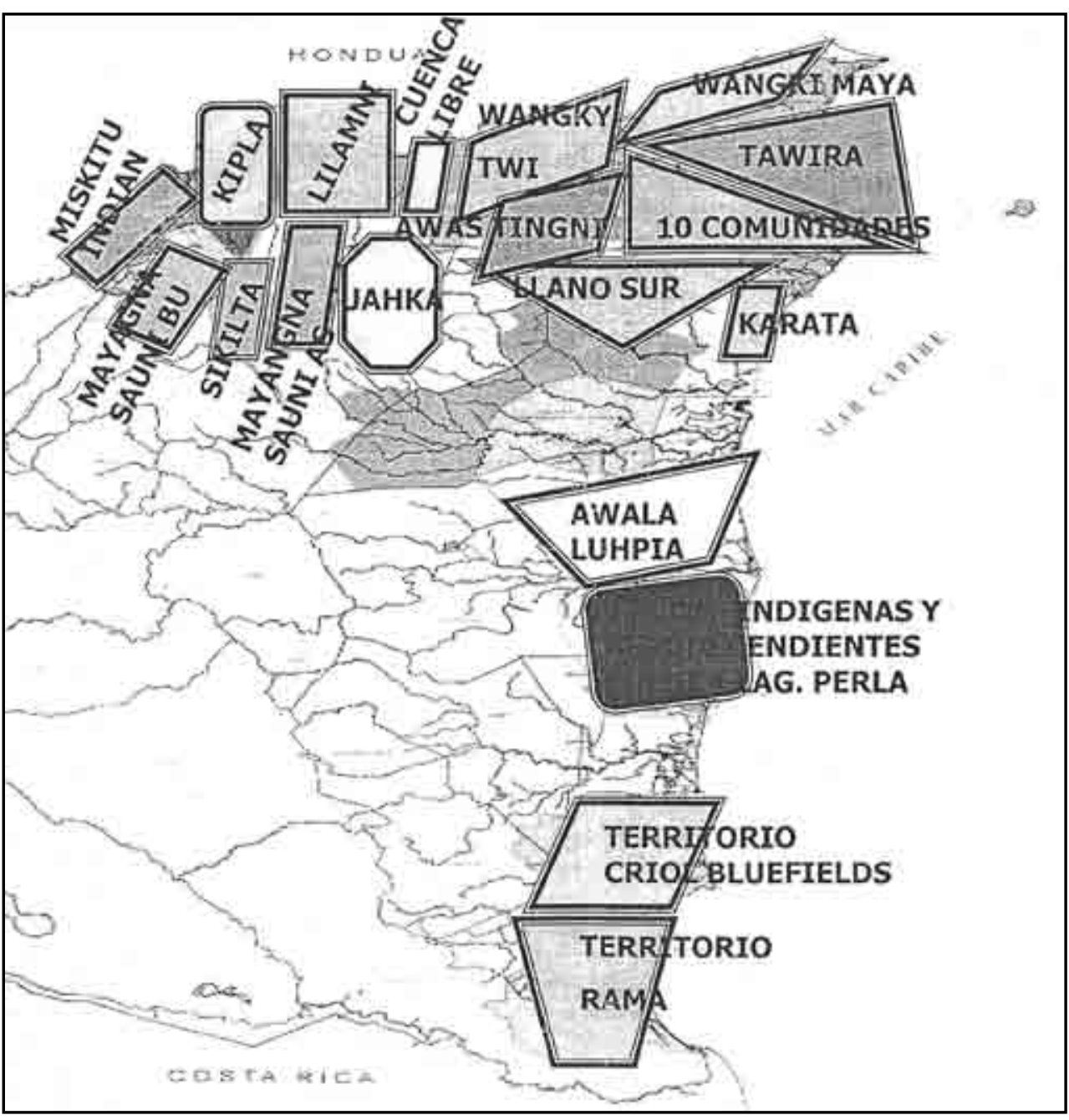

Mapa territorial de la demarcación.

La segunda dimensión, carencia del pluralismo en el proceso autonómico, se refiere a la falta de heterogeneidad de organizaciones en los espacios autonómicos, por ausencia de organizaciones étnico-comunitarias. En los espacios autonómicos prevalece la homogeneidad de identidades organizativas, privilegiando absolutamente a los partidos.

Con la presencia de tres partidos nacionales (FSLN, PLC, ALN) y un partido regional (YATAMA) se justifica el pluralismo haciendo un traslado mecánico de la aplicación del concepto en realidades específicas totalmente diferentes de la sociedad costeña. E1 pluralismo, en el caso del espacio autonómico, se define mediante la participación heterogénea de organizaciones diferenciadas por su naturaleza en oposición a participación homogénea a través de multiplicidad de organizaciones de la misma naturaleza: partidos. Este tipo de prácticas del pluralismo no satisface la representación de los genuinos intereses comunitarios y

de los partidos. Una interpretación más de(ojo, eliminar la d) cercana a este planteamiento permite comprender que en éste subyace como causa un fuerte cuestionamiento hacia los partidos y el rol de los mismos. El cuestionamiento hacia los partidos alcanza dos dimensiones. Una, la incompatibilidad de los partidos con la identidad y principios comunitarios. Otra, la carencia del pluralismo en el proceso autonómico, obstaculizando en conjunto las posibilidades de la democracia y el desarrollo en la Costa Caribe.

La incompatibilidad de los partidos con los principios y la identidad comunitaria es por considerar los partidos como aparatos políticos y jurídicos de la clase económica dominante del Pacífico y Caribe nicaragüense, organizados en función de los intereses particulares y de la propiedad privada. Esto contradice de esencia, el origen social de los comunitarios y la identidad colectiva basada en la propiedad comunal de la tierra. se niega la posibilidad de auto desarrollo comunitario.

La principal institución del proyecto autonómico en ambas regiones son los consejos regionales, compuestos por 45 concejales. Los consejos regionales, debiendo ser instancia representativa de todo el universo de la sociedad, solamente cuatro partidos tienen derecho a espacios en los mismos. Puede haber otros cuatro o más. No importa la cantidad de partidos nacionales o de corte regional, pero eso no define el pluralismo en el proceso autonómico. Se reitera, el pluralismo se define con la participación heterogénea de organizaciones diferenciadas por la naturaleza de las mismas. Esto pasa por la participación de organizaciones étnicocomunitaria surgidas de las Asambleas Comunales. Por la representación homogénea o falta de pluralismo en los consejos regionales, esta institución se convierte en espacio proclive para la producción y reproducción de corrupción y la impunidad. 
Entre los sectores miskitos, el sentimiento anti partidario es más intenso aún hacia YATAMA. Esto obedece a una serie de razones que tienen que ver con las decisiones anti comunitarias adoptadas por la dirigencia: convertir la organización en partido; contraer alianzas con partidos; percepción de graves actos de corrupción por miembros prominentes del partido en la administración autonómica y municipalidades; impunidad de los actos de corrupción; ineficacia en la gestión pública; indiferencia ante las demandas de la población; prácticas de negación de derechos de ciudadanía a los comunitarios por privilegiar criterios de militancia político-partidaria para acceso a oportunidades dentro del proceso autonómico. Ante las bases comunitarias, estas prácticas constituyen en conjunto actos de negación a la identidad e intereses comunitarios.

El movimiento de los ancianos tiene internamente serias limitaciones y contradicciones propias. De no superar las mismas, seguramente limitará la capacidad de poner en práctica su propuesta a mediano plazo. Otras limitaciones son externas y pasan por orden financiero que merecen concurso externo. El fracaso de las jornadas de octubre es fracaso de todos. Pero hay posibilidad de salvar si hay voluntad real de luchar por el desarrollo.

\section{BIBLIOGRAFIA}

García, Claudia (2007): Etnogénesis, hibridación y consolidación de la identidad del pueblo miskitu: Madrid, Gráficas Varona, S.A., pp. 25

Larson, Anne M y Mendoza, Yadder (2009): Desafios en la tenencia comunitaria de bosques en la RAAN de Nicaragua: Managua, URACCAN, $1^{\text {a }}$ ed.

Matamoros, Ruth (2009): “Una Nación más allá de las Fronteras”. WANI, Revista del Caribe Nicaragüense eneromarzo, No. 56: Managua, BICU-CIDCA, pgs. 27-30.

PNUD (2005), Informe de Desarrollo Humano. Las Regiones Autónomas de la Costa Caribe. ¿Nicaragua asume su diversidad?: Managua, PNUD, 1'a . ed. Pp.xxi, 39,87

Roldán, Roque Ortega (2000). LEGALIDAD Y DERECHOS ETNICOS EN LA COSTA ATLÁNTICA DE NICARAGUA, Talleres Grafisa, S.A., Bogotá DC, Colombia. Pp. 26,188

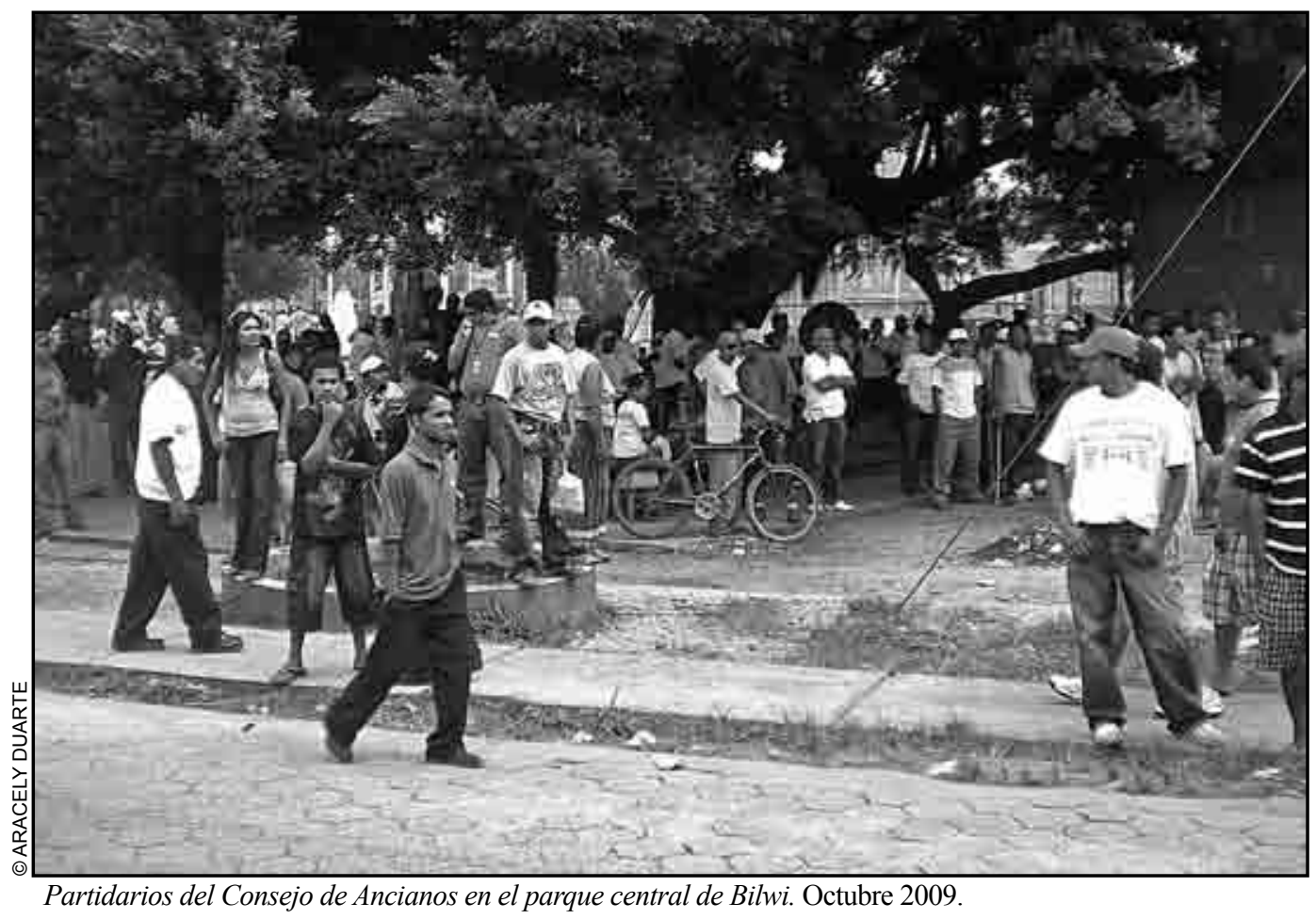

